\title{
Biodegradation of Polyvinyl Alcohol-Based Binary Composites
}

\author{
Lubov N. Studenikina, Vladimir I. Korchagin, \\ Lubov V. Popova* and Pavel N. Savvin \\ Voronezh State University of Engineering Technologies \\ Voronezh, Russian Federation
}

Received 16.12.2020, received in revised form 17.01.2021, accepted 12.03.2021

\begin{abstract}
The behavior of binary composites (BC) containing polyvinyl alcohol (PVA-1799) and various amounts of microcellulose (MC) in water and biochemical media (soil, compost, water-silt mixture) is studied. The results of the experiment emphasize the complex nature of the biodegradation of the studied composites under natural conditions. Introduction of microcellulose into the polymer matrix of PVA about $60 \mathrm{vol} \%$ is accompanied by the formation of a porous structure that promotes the penetration of water and components of biochemical media into the volume of the material. At the same time, the uniform distribution of the MC fibers creates the effect of a reinforcing filler and allows you to maintain strength even with prolonged soaking of the BC. The achievement of «zero» strength at exposure in water is observed after 2 days, 14 days, 2 months. for BC with a content of MC 0, 80-60, 40-10 vol.\%, respectively. After 6 months of incubation in the soil environment, the index of destruction of composites was $0.89,0.87,0.95,0.96$ with a degree of filling with microcellulose of 10, 20,40, 80 vol.\%, respectively, while there was a lack of fragmentation of the samples. A method of computer colorometry in the dynamics of biodegradation of polysaccharide-filled thermoplastics is proposed to assess the degree of penetration of components of biochemical media into the volume of the material.
\end{abstract}

Keywords: biodegradation, binary composites, polyvinyl alcohol, microcellulose, composting, environment, biodegradation standards.

Citation: Studenikina L. N., Korchagin V.I., Popova L. V., Savvin P. N. Biodegradation of polyvinyl alcohol-based binary composites, J. Sib. Fed. Univ. Chem., 2021, 14(1), 111-119. DOI: 10.17516/1998-2836-0221

(C) Siberian Federal University. All rights reserved

This work is licensed under a Creative Commons Attribution-NonCommercial 4.0 International License (CC BY-NC 4.0).

* Corresponding author E-mail address: lubov-churkina@yandex.ru 


\title{
Биодеградация бинарных композитов \\ на основе поливинилового спирта
}

\author{
Л.Н. Студеникина, В.И. Корчагин, \\ Л. В. Попова, П.Н. Саввин \\ Воронежский государственный университет \\ инженерных технологий \\ Российская Федерация, Воронеж
}

\begin{abstract}
Аннотация. Исследовано поведение бинарных композитов (БК), включающих поливиниловый спирт (ПВС) марки 1799, с различным содержанием микроцеллюлозы (МЦ) в воде и биохимических средах: почве, компосте, водно-иловой смеси. Результаты эксперимента подчеркивают сложный характер биодеградации исследуемых БК в естественных условиях. Введение МЦ порядка 60 об. \% в полимерную матрицу ПВС сопровождается образованием пористой структуры, способствующей проникновению воды и компонентов биохимических сред в объем материала, при этом равномерное распределение волокон МЦ создает эффект армирующего наполнителя и позволяет сохранять прочность даже при длительном вымачивании БК. Достижение «нулевой» прочности (т. е. такое состояние образца, которое не позволяет провести испытание, так как материал разрушается в руках) при экспозиции в воде наблюдается через 2 сут, 14 сут, 2 мес. для БК с содержанием МЦ 0, 80-60, 40-10 об. \% соответственно. Через 6 месяцев инкубации в почвенной среде индекс деструкции БК составил $0.89,0.87,0.95,0.96$ при степени наполнения 10, 20, 40, 80 об. \% соответственно, при этом наблюдалось отсутствие фрагментации образцов. Предложен метод компьютерной цветометрии в динамике процесса биодеградации наполненных полисахаридами термопластов для оценки степени проникновения компонентов биохимческих сред в объем материала.
\end{abstract}

Ключевые слова: биодеградация, бинарные композиты, поливиниловый спирт, микроцеллюлоза, компостирование, окружающая среда, стандарты биоразложения.

Цитирование: Студеникина, Л.Н. Биодеградация бинарных композитов на основе поливинилового спирта / Л. Н. Студеникина, В. И. Корчагин, Л. В. Попова, П. Н. Саввин // Журн. Сиб. федер. ун-та. Химия, 2021, 14(1). С. 111119. DOI: 10.17516/1998-2836-0221

Снижение негативного воздействия на окружающую среду (OC) пластиковых отходов является одной из приоритетных экологических задач XXI века. Замена неликвидных при вторпереработке пластиков на биоразлагаемые (компостируемые) аналоги позволит решить проблему их утилизации путем совместной переработки с органическими фракциями отходов с получением целевых продуктов (компостов, почвогрунтов и пр.).

Актуальным направлением исследований в области создания и переработки биоразлагаемых полимерных материалов является разработка компостируемых композитов с требуемыми эксплуатационными свойствами при высоких технико-экономических показателях производства, что требует изучения степени влияния технологических факторов 
на структурообразование и физико-механические характеристики с учетом биодеградации в природных средах. Не менее важная проблема - анализ корреляции методов оценки биодеградации (лабораторных и натурных, прямых и косвенных).

Технологии получения биоразлагаемых полимеров развиваются уже более 20 лет, однако такие компостируемые пластики, как полилактид, полигидроксибутират и прочие продукты микробиологического синтеза, а также сшитые природные полимеры (полисахариды, белки), до сих пор не получили массового распространения из-за высокой стоимости и сложности получения. Бинарные композиты (БК) на основе синтетических термопластов более привлекательны с технико-экономической точки зрения, но ключевым фактором эффективности их использования признана способность полимерной матрицы к биодеградации.

Одним из немногих синтетических термопластов, способных к биодеградации, является поливиниловый спирт (ПВС), который включен в перечень биоразлагаемых пластиков по ГОСТ Р 57432-2017 и стоимость которого в несколько раз ниже, чем у биоразлагаемых полимеров микробиологического происхождения. Широкое использование ПВС ограничено низкой влагостойкостью и стабильностью эксплуатационных свойств.

В качестве полимерной матрицы БК представляет интерес ПВС с высокой молекулярной массой $\left(10^{5} \div 10^{6}\right)$ и низким содержанием винилацетатных групп (не более 1,0 масс. \%), например, марки 1799, что способствует водостойкости и более высокой температуре размягчения, так как наличие ацетильных групп в виде короткоцепочечных ответвлений снижает кристалличность полимеров и, как следствие, физико-химические и прочностные показатели.

Перспективность применения композитов на основе ПВС и полисахаридов (ПС) отмечают многие исследователи [1-5], при этом в качестве дисперсной фазы целесообразно использовать крахмал или целлюлозу как наиболее доступные и способные биодеградации. Применение микроцеллюлозы (МЦ) с размером частиц до 200 мкм в полимерных композициях в отличие от порошковой целлюлозы, размер частиц которой достигает 2000 мкм, имеет ряд преимуществ: возможность формования тонкостенных изделий и пленок, повышение прочностных показателей материала и пр. [6].

Модификация ПВС наполнителями и добавками изменяет структуру макромолекул, в частности, стереорегулярность и связанную с ней кристалличность [7], а «сшивка» макромолекул ПВС при технологической обработке может приводить к снижению растворимости и диффузии ферментов в материал [8], что снижает скорость биодеградации.

Процессы биодеструкции ПВС исследованы в работах [9-13], полученные результаты свидетельствуют о сложном характере деградации данного полимера в ОС. Исследования влияния стереорегулярности ПВС на его биодеградируемость в присутствии бактерии-деструктора Pseudomonassp. (по показателю снижения общего органического углерода (ТОC) в культуре PVA) показали, что изотактический ПВС (i-PVA), имеющий ряд длинных мезопоследовательностей, восприимчив к биодеградации, а ПВС с высокой синдиотактичностью (s-PVA) - нет [13].

В настоящее время разработано большое количество методов оценки биодеструкции полимерных материалов, отличающихся продолжительностью, уровнем регламентации, определяемым параметром биоразлагаемости и т. д. Натурные методы, несмотря на их длительность и трудоемкость, позволяют получить наиболее достоверные данные о кинетике и механизме биодеструкции материалов, чем лабораторные, так как позволяют одновременно подвергать 
материалы всему комплексу внешних воздействий окружающей среды. Недостаток натурных испытаний состоит в том, что в естественной среде происходит непрерывное изменение ее химического и микробиологического состава, температуры, влажности, кислотности, условий аэрирования и т. д., что создает трудности в интерпретации результатов [14].

Следует отметить, что при проведении и лабораторных, и натурных испытаний возникает проблема количественной оценки степени биоповреждений, ибо не всегда возможно с допустимой степенью погрешности оценить изменение физических показателей материала, а визуальная характеристика может быть весьма субъективной.

Цель работы: оценка влияния биохимических воздействий на бинарные композиты, предназначенные для изготовления компостируемых упаковочных материалов, включающие поливиниловый спирт с высокой молекулярной массой $\left(10^{5} \div 10^{6}\right)$ и низким содержанием остаточных ацетатных групп, в зависимости от содержания микроцеллюлозы.

В качестве объектов исследования были выбраны БК в виде пластин $5 \times 10$ см и толщиной $200 \div 800$ мкм (в зависимости от степени наполнения), полученные с использованием ПВС марки 1799 и МЦ марки Filtracell при содержании от 10 до 80 \% (об.) БК изготавливали методом жидкофазного наполнения р-раПВС (5 \%) и тонкодисперсной МЦ с последующим обезвоживанием пленочных образцов в вакуум-сушильном шкафу.

Макроструктуру полимерных композитов оценивали с помощью цифрового микроскопа Levenhuk-D670T с программным обеспечением LevenhukToupView. Прочностные показатели определяли по ГОСТ 11262-17 с помощью разрывной машины РМ-50 с программным обеспечением «StretchTest». Определение прочности БК до вымачивания осуществлялось после 24-часового кондиционирования приготовленных образцов на воздухе в нормальных условиях (влажность воздуха $75 \%$, температура $20^{\circ} \mathrm{C}$ ), определяли прочность после вымачивания через 5 мин ( \pm 10 c) после изъятия образца из воды. Оценку водопоглощения БК проводили в соответствии с ГОСТ 4650-2014.

Качественную и количественную оценки воздействия биохимических сред на БК с различным содержанием МЦ проводили с использованием метода компьютерной цветометрии. Образцы БК, подвергнутые экспозиции определенной продолжительности, извлекали из биохимических сред, очищали поверхность от механических загрязнений, после чего сканировали в цветовом режиме TrueColor (оптическое разрешение $300 \mathrm{dpi}$, размер не менее $100 \times 100$ pix). Для стандартизации результатов и исключения погрешности цветопередачи сканирование проводили в присутствии белого листа с нанесенной спектральной шкалой и шкалой яркости (для автоматического определения баланса белого), обрабатывали изображения при помощи некоммерческой программы ImageJ 1.46. За результат принимали среднеарифметическое значение каждой из цветовых компонент и интенсивность окраски.

Оценку биохимического воздействия на образцы БК проводили после экспозиции в средах: почве (чернозем типичный), компосте (масса на конечной стадии созревания отходов растительного происхождения), суспензии природного ила (водно-иловая смесь). Почвенный тест и компостирование осуществляли в течение 6 месяцев с периодическим увлажнением и перемешиванием. Биохимическое воздействие на БК природного ила проводили в течение 2-недельного пребывания в лабораторном аэротенке, более длительное пребывание природного ила в искусственно созданных условиях неизбежно сопровождается сменой биоценоза. 
Водопоглощение ПВС марки 1799 (образец в виде пластины 1 х 1 см и толщиной 200 мкм) при температуре $20{ }^{\circ} \mathrm{C}$ и $\mathrm{pH}=7,0$ достигает $800 \%$ по массе в первые 5 мин экспозиции. Введение МЦ снижает водопоглощение не только за счет сокращения общего объема ПВС в бинарном композите, но и за счет структурных изменений в период набухания полимера, замедляющих диффузию воды (коэффициент диффузии снижается пропорционально снижению содержания МЦ в БК до конкретного предела).

На рис. 1 отражена зависимость водопоглощения БК от содержания МЦ.

Отмечено, что содержание МЦ порядка 60-65 об. \% является критическим значением, так как нарушается сплошность полимерной матрицы БК, что сопровождается образованием пористой структуры за счет дефицита полимерного связующего. Поведение высоконаполненных композитов ПВС: МЦ в воде соответствует поведению макропористых материалов, открытая структура которых делает возможным быструю сорбцию жидкости в направлении центра высушенной матрицы за счет действия капиллярных сил [15].

Водопоглощение композитов ПВС: МЦ сопровождается резким изменением физикомеханических свойств материала, что связано с разбуханием МЦ, пластифицирующим действием воды на ПВС, и последующим гелеобразованием. Оценка изменения прочности в динамике вымачивания необходима для прогнозирования эксплуатационных свойств композитов, а также возможности их гидролитической деструкции. Следует отметить, что при оценке прочностных показателей материалов на основе ПВС крайне важно обеспечить одинаковую влажность образцов и окружающей среды, поскольку с изменением влажности искажаются диаграммы растяжения.

Установлено, что модуль Юнга для ненаполненного ПВС через 1 сут вымачивания снизился в 5000 раз, для композита ПВС: МЦ при 20 об. \% наполнения - в 230 раз, при 40 об. \% наполнения - в 285 раз. Через 14 сут вымачивания ненаполненный ПВС показал «нулевую» прочность (состояние образца не позволяет провести испытание, так как он разрушается в руках), а композиты ПВС: МЦ сохранили форму и достаточную для испытания прочность. Выявлено, что при повышении в БК содержания МЦ с 20 до 40 об. \% модуль Юнга при вымачивании композитов снижается с 0,015 до 0,007 через 1 сут вымачивания и с 0,008 до 0,004 через 14 сут вымачивания, т. е. отмечается прямолинейная зависимость.

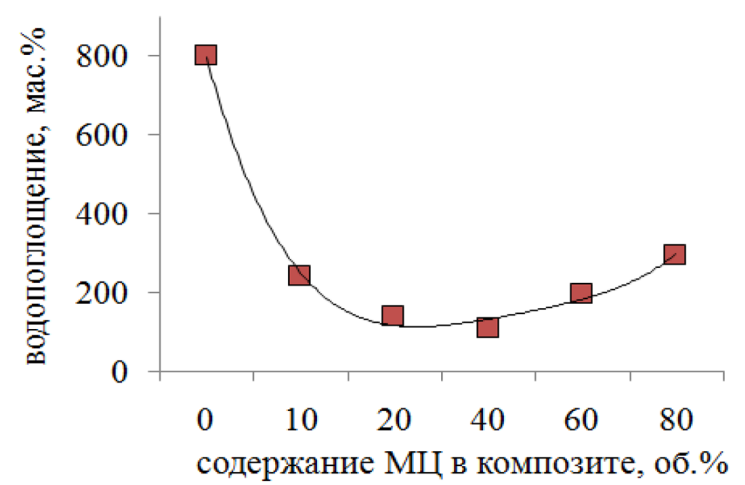

Рис. 1. Влияние степени наполнения ПВС на водопоглощение композита

Fig. 1. Influence of the degree of PVA filling on the water absorption of the composite 
Равномерное распределение волокон целлюлозы в полимерной матрице БК создает эффект армирующего наполнителя и позволяет сохранять прочность даже при длительном вымачивании. На рис. 2 показана динамика изменения прочностных показателей композитов на основе ПВС1799 при вымачивании в воде в течение двух месяцев.

Графические зависимости для образцов ПВС и БК с содержанием МЦ 40 \% (об.) обрываются в точках 48 ч и 14 сут соответственно, так как в следующем периоде испытаний материал показал «нулевую» прочность. Изначально вымачивание (рис. 2) сопровождается снижением прочности и повышением удлинения (пластификация без деструкции полимерной цепи) с выходом зависимости прочностных показателей на плато, но через определенное время при снижении прочности начинает снижаться и относительное удлинение, что говорит о деструктивных процессах в полимерной матрице.

Механизм биодеградации гетерогенных пористых БК, содержащих ПВС и МЦ, во влажных биохимических средах включает стадии проникновения воды и микроорганизмов в поры БК, гидролитической деструкции полимерной матрицы, ферментативной деструкции МЦ, что в начальный период биодеградации отображается на макрофотографиях в виде трещин, «потемнения» пор и развития в них мицелия (рис. За и б).

Процессы биодеградации протекают при наличии влаги, однако высокие значения способности материала к сорбции воды и диффузии водяного пара не гарантируют высокой скорости биодеградации [16]. В микробной атаке на биодеградируемый материал участвует не один вид, а ассоциация микроорганизмов, взаимно влияющих друг на друга и вырабатывающих ферменты, участвующие в разрушении материала [17]. Наибольшую роль в микробной атаке играют бактерии Cytophaga, Bacillus, Streptomyces, Micobacterium, Pseudomonas, мицеллярные грибы и дрожжи Aspergillus, Alternaria, Penicillium, Trichoderma и ряд других [16]. В работе [9] установ-
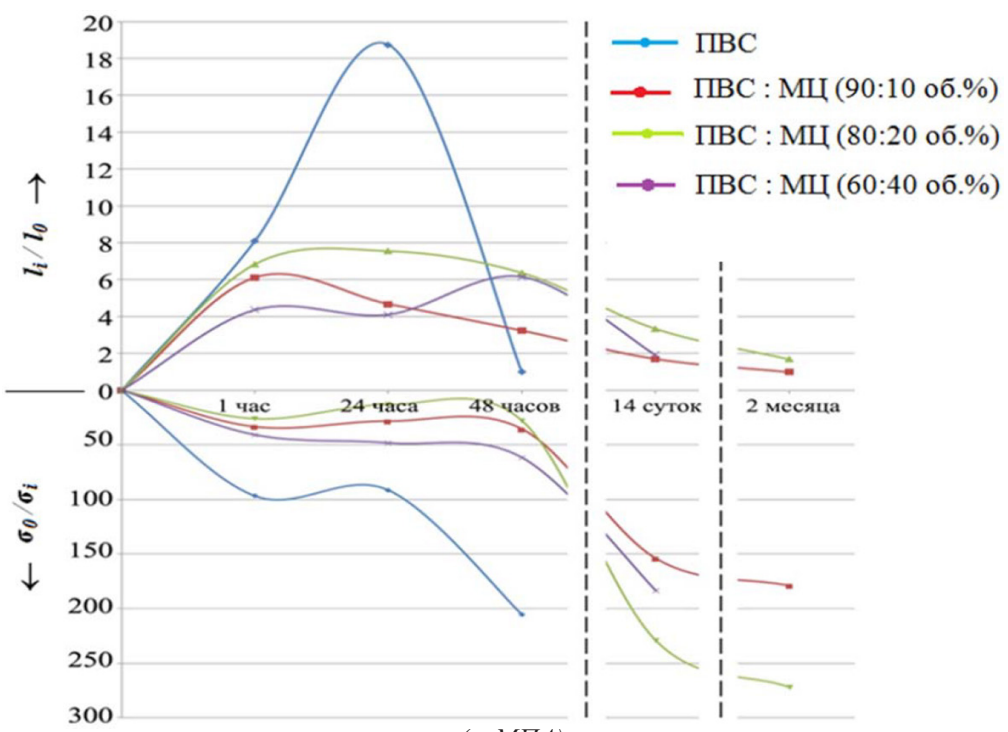

$\left(\sigma_{0} / \sigma_{i}\right)$-кратность снижения прочности при разрыве $(\sigma, M \Pi A)$,

$\left(l_{i} / l_{0}\right)$ - кратность повышения относительного удлинения при разрыве $(l, \%)$

Рис. 2. Изменение прочностных показателей БК в динамике вымачивания

Fig. 2. Changes in the strength parameters of binary composites in the dynamics of soaking 
лено, что биодеструкция ПВС осуществляется с помощью ферментов ПВА-оксидазы и алкогольдегидрогеназы, однако бактерия, продуцирующая необходимый фермент (бактерия Sphingomona $s s p$, выделенная из активного ила), требует определенных факторов роста и симбиотического взаимодействия с другими представителями биоценоза, что не всегда осуществимо на практике.

При воздействии природных сред (почва, компост, ил) на полимерные композиты, содержащие полисахариды и способные к проникновению в объем материала влаги и микроорганизмов с последующей биодеградацией, происходит изменение окраски.

Обработка результатов цветометрической оценки образцов (рис. 4) показала схожесть динамики изменения окраски БК в почве и компосте, для водно-иловой смеси изменение окраски оказалось менее интенсивным (набухание ПВС и МЦ сопровождается сужением и закрытием пор, что не позволяет проникать компонентам ила в объем композита в период исследования). За три месяца биодеградации в условиях компоста и почвы интенсивность окраски композитов ПВС: МЦ снизилась в 4-5 раз.
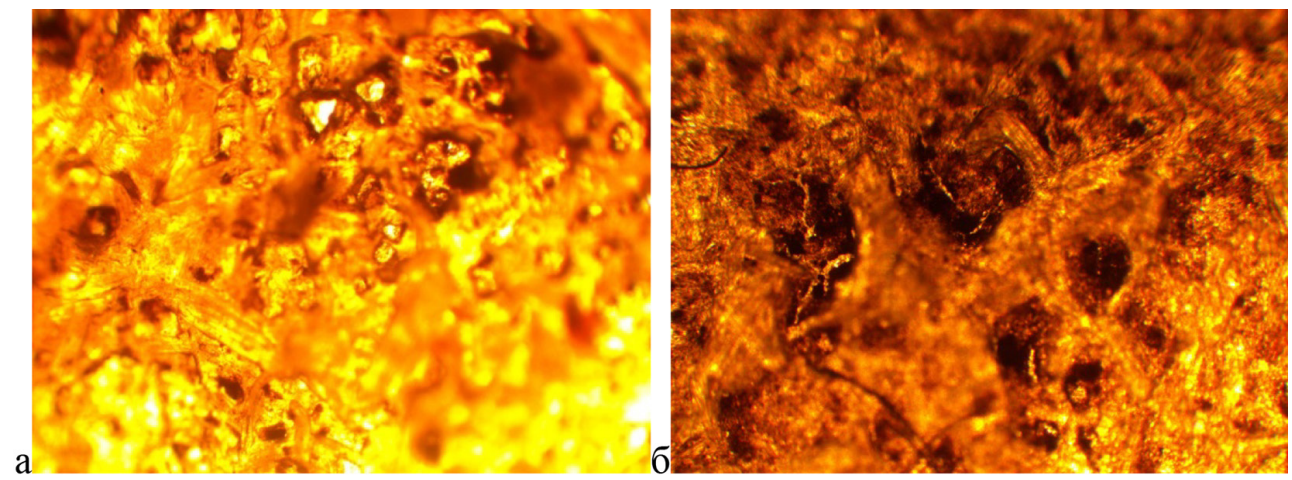

Рис. 3. Макроструктура композита на основе ПВС с содержанием МЦ $60 \%$, об.: а - через 1 месяц инкубации в компосте; б - через 1 месяц инкубации в почве

Fig. 3. Macrostructure of a composite based on PVA with a content of $60 \% \mathrm{MC}$, vol.: a - after 1 month of incubation in compost; $b$ - after 1 month of incubation in soil
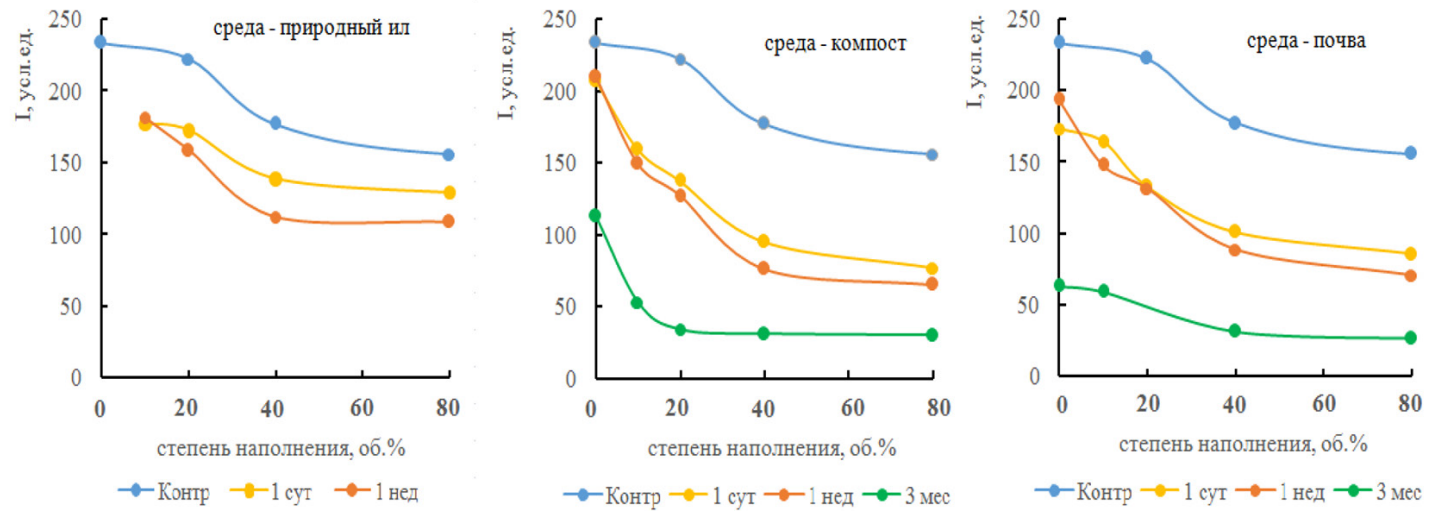

Рис. 4. Динамика изменения интенсивности окраски (I, усл.ед.) наполненного микроцеллюлозой ПВС в различных биохимических средах

Fig. 4. Dynamics of changes in the color intensity of PVA filled with microcellulose in various biochemical media 
Показатели потери прочности композитных материалов позволяют удобно и достоверно оценить скорость деструктивных процессов в полимерной матрице под воздействием различных факторов. При этом используется термин «индекс деструкции (ID)»- отношение фактической убыли какой-либо физической величины полимера (молекулярной массы, предела прочности при разрыве и др.) к максимально возможной. Если один и тот же материал показывает различные ID под воздействием тех или иных внешних факторов, это свидетельствует о различных механизмах разложения, протекающих внутри полимерной матрицы [18]. ID (по показателю потери прочности при разрыве) композитов ПВС: МЦ со степенью наполнения 10, $20,40,80$ об. \% после 6-месячной инкубации в почвенной среде составил 0,$89 ; 0,87 ; 0,95$ и 0,96 соответственно. При этом для образцов отмечено сохранение целостности формы (отсутствие фрагментации), что не позволяет отнести такой материал к категории компостируемых пластиков по ГОСТ Р 57226-2016.

Таким образом, результаты эксперимента подчеркивают сложный характер биодеградации БК на основе ПВС с высокой молекулярной массой и низким содержанием ВА-групп в естественных биохимических условиях ОС. С одной стороны, введение МЦ в полимерную матрицу ПВС сопровождается образованием пористой структуры, способствующей проникновению воды и компонентов биохимических сред в объем материала, с другой - равномерное распределение волокон целлюлозы создает эффект армирующего наполнителя и позволяет сохранять прочность даже при длительном вымачивании БК. Предложен метод компьютерной цветометрии в динамике биодеградации наполненных полисахаридами термопластов для оценки степени проникновения компонентов биохимических сред в объем материала.

\section{Список литературы / References}

1. Begum M.H.A., Hossain M.M., Gafur M.A. Preparation and characterization of polyvinyl alcohol-starch composites reinforced with pulp. SN Appl. Sci. 1, 1091 (2019).

2. Guo B., Zha D., Li B., Yin P., Li P. Polyvinyl alcohol microspheres reinforced thermoplastic starch composites. Materials. 2018. Vol. 11. No. 4. P. 640-643

3. Qiu K, Netravail AN. Polyvinyl alcohol based biodegradable polymer nano-composites, biodegradable polymers. Nova Science Publishers Inc., New York, 2015. P. 325-379

4. Папкина В. Ю., Малинкина О.Н., Шиповская А.Б. и др. Свойства, деградация в почвогрунте и фитотоксичность композитов крахмала с поливиниловым спиртом. Изв. Сарат. yн-та. Нов. сер. Сер. Химия. Биология. Экология. 2018. Т. 18, вып. 1. С. 25-35 [Papkina V. Yu., Malinkina O.N., Shipovskaya A.B. etc. Properties, degradation in soil and phytotoxicity of starch composites with polyvinyl alcohol. Izv. Sarat. un-ta. New. ser. Ser. Chemistry. Biology. Ecology. 2018. Vol. 18, issue 1. P. 25-35 (In Russ.)]

5. Павленок А.В., Давыдова О. В., Дробышевская Н. Е. и др. Получение и свойства биоразлагаемых композиционных материалов на основе поливинилового спирта и крахмала. Вестник ГГТУ им. П. О. Сухого 2018. № 1. С. 38-46 [Pavlenok A. V., Davydova O. V., Drobyshevskaya N.Е. etc. Preparation and properties of biodegradable composite materials based on polyvinyl alcohol and starch. Vestnik GSTU im. P. O. Sukhogo. 2018. No. 1. P. 38-46 (In Russ.)]

6. Корчагин В.И., Студеникина Л.Н., Шелкунова М.В. Реологическое поведение бинарной полимерной композиции. Пластические массы. 2019. № 9-10. С. 52-55 [Korchagin V.I., 
Studenikina L.N., Shelkunova M.V. Rheological behavior of a binary polymer composition. Plasticmasses. 2019. No. 9-10. P. 52-55 (In Russ.)]

7. Лазарева Т.Г., Ильющенко И.А., Алимов И.Ф. Пленочные материалы на основе поливинилового спирта и поликислот. Высокомолекулярные соединения. Серия А 1994. Т. 36. № 9. C. 1481-1485 [Lazareva T. G., Ilyushchenko I. A., Alimov I. F. Filmmaterials base donpolyvinyl alcoholand polyacids. Polymer Science. Series A 1994. Vol. 36. No. 9. P. 1481-1485 (In Russ.)]

8. Моргачева А.А. Гидрогели на основе модифицированного поливинилового спирта и модифицированного 2-гидроксиэтилкрахмала. Дисс. канд. химич. наук. Москва, 2019. 160 с. [Morgacheva A.A. Hydrogels based on modified polyvinyl alcohol and modified 2-hydroxyethyl starch. Diss. Cand. chemical sciences. Moscow, 2019. 160 p. (In Russ.)]

9. Vaclavkova T., Ruzicka J., Julinova M. Novelaspectsofsymbiotic (polyvinylalcohol) biodegradation. Appl Microbiol Biotechnol. 2007. Vol. 76. P. 911-917.

10. Tokiwa Y., Kawabata G., Jarerat A. A modified method for isolating poly(vinyl alcohol)degrading bacteria and study of their degradation patterns. Biotechnology Letters. 2001. Vol. 23. P. 1937-1941.

11. Amann M., Minge O. Biodegradability of Poly(vinyl acetate) and Related Polymers. Advances in Polymer Science. 2011. Vol. 245. P. 137-172.

12. Kim B.C., Shon C.K., Lim S.K., Lee J.W., Park W. Degradation of polyvinyl alcohol by Sphingomonas sp. SA3 and its symbiote. J Ind Microbiol Biotechnol. 2003. Vol. 30. P. 70-74

13. Fukae Ryohei, Nakata Koji, Takeo Masahiro, Yamamoto Tohei, Sangen Osamu. Biodegradation of PVAs with Various Stereoregularities. Fiber. 2000. Vol. 56. No. 5. P. 254-258

14. Крутько Э.Т., Прокопчук Н.Р., Глоба А.И. Технология биоразлагаемых полимерных материалов. Минск: БГТУ, 2014. 105 с. [Krutko E.T., Prokopchuk N. R., Globa A. I. Technology of biodegradable polymer materials. Minsk, BSTU, 2014. 105 p. (In Russ.)]

15. Артюхов А.А. Сшитые гидрогели поливинилового спирта и их биомедицинское применение. Дисс. д-ра хим. наук. Москва, 2017. 307 с. [Artyukhov A. A. Cross-linked polyvinyl alcohol hydrogels and their biomedical application. Diss. Doctor of Chemical Sciences. Moscow, 2017. 307 p. (In Russ.)]

16. Mikhail I. Shtilman. Biodegradation of Polymers. Journal of Siberian Federal University. Biology 2. 2015. Vol. 8. P. 113-130.

17. Kaygorodov K.L., Tarabanko V.E., Morozov A. A., Smirnova M. A. Synthesis and properties of biodegradable copolymers based on $\varepsilon$-caprolactam and $\alpha$-angelicalactone, J. Sib. Fed. Univ. Chem. 2019. Vol. 12(4). P. 503-511.

18. Korchagin V.I., Surkova A.M., Studenikina L.N., Protasov A.V. Influence of prooxidant nature on evolution of formaldehyde from oxo-degradable polyethylene. Izv. Vyssh. Uchebn. Zaved. Khim. Khim. Tekhnol. 2019. Vol. 62. No. 2. P. 101-107. 